\title{
Using Digital Technology to Engage and Communicate with Patients: A Survey of Patient Attitudes
}

\author{
Brian $P$ Jenssen, $M D^{1,2}$, Nandita Mitra, $P h D^{3,6}$, Anand Shah, MD, MSHP4, Fei Wan, MS ${ }^{3}$, and \\ David Grande, MD, MPA 5,6
}

\begin{abstract}
'Robert Wood Johnson Foundation Clinical Scholars Program, University of Pennsylvania, Philadelphia, PA, USA; ${ }^{2}$ Division of General Pediatrics, Department of Pediatrics, The Children's Hospital of Philadelphia, Philadelphia, PA, USA; ${ }^{3}$ Department of Biostatistics and Epidemiology, University of Pennsylvania Perelman School of Medicine, Philadelphia, PA, USA; ${ }^{4}$ CCCI, Dallas, TX, USA; 5 Division of General Internal Medicine, Department of Medicine, University of Pennsylvania Perelman School of Medicine, Philadelphia, PA, USA; ${ }^{\circ}$ Leonard Davis Institute of Health Economics, University of Pennsylvania, Philadelphia, PA, USA.
\end{abstract}

BACKGROUND: As primary care moves toward a system of population health management, providers will need to engage patients outside traditional office-based interactions.

OBJECTIVE: We assessed patient attitudes regarding technology use to communicate with their primary care team or to engage with other patients outside typical office settings.

Design/Participants/Main Measures

We conducted a national survey using GfK KnowledgePanel ${ }^{\circledR}$ to examine attitudes on the use of digital technology (email, text messaging, and social media such as Facebook and Twitter) to communicate with primary care teams about health behavior goals and test results. We also assessed attitudes toward the use of digital technologies to engage with other patients in activities such as peer coaching.

KEY RESULTS: Of the 5119 panel members invited to participate, 3336 completed the survey (response rate, $65.2 \%)$. Among respondents, more than half (58\%) reported using Facebook, and nearly two-thirds (64.1 \%) used text messaging. Overall, few participants were willing to communicate about health goals via social media $(3.1 \%)$ or text messaging (13.3\%), compared to email $(48.8 \%)$ or phone (75.5\%) (results were similar for communication about test results). Among those that used text messaging, race/ethnicity was the only factor independently associated with greater support for text messaging [African American (OR 1.44; 95 \% CI, 1.01-2.06) and Hispanic (OR 1.8; $95 \%$ CI, 1.25-2.59)] in multivariate models. Participants interested in engaging in peer coaching through Facebook (11.7\%) were more likely to be younger $(p<0.0001)$, female $(\mathrm{p}<0.001)$, and a racial/ ethnic minority (African American, non-Hispanic or Hispanic, $p<0.0004$ ).

CONCLUSIONS: Despite regular use of new digital technology such as text messaging and social media, few participants supported using these tools for communicating with their physicians' practice. Participants were most supportive of using email for communication. Contrary to previous studies, among users of technology, low

Received June 2, 2015

Revised September 4, 2015

Accepted September 10, 2015

Published online September 18, 2015 socioeconomic status and racial/ethnic minorities were equally or more likely to support use.

KEY WORDS: technology use; patient engagement; text messaging; email; social media.

\section{ABBREVIATIONS}

PCMH Patient-centered medical home

EHRs Electronic health records

GEE Generalized estimating equations

$\mathrm{J}$ Gen Intern Med 31(1):85-92

DOI: $10.1007 / \mathrm{s} 11606-015-3517-\mathrm{x}$

(c) Society of General Internal Medicine 2015

\section{INTRODUCTION}

The patient-centered medical home (PCMH), combined with new payment models such as accountable care organizations, shared savings programs, and bundled payments, are moving primary care toward a system of population health management. ${ }^{1-11}$ A critical component of population management requires proactive, regular interaction between patients and the clinician or clinical team-engagement and communication that will take place outside the traditional face-to-face encounter. ${ }^{12-18}$ Outreach outside of physician visits, for example, has been shown to improve colorectal cancer screening, ${ }^{19}$ increase influenza vaccination, ${ }^{20,21}$ reduce medical costs and hospitalizations, ${ }^{22}$ and improve care and health outcomes for patients with chronic care conditions. ${ }^{23}$ Consumer e-health tools - electronic tools and services, including secure messaging between patients and providers, mobile health (mHealth) apps, and existing technologies used in novel way$\mathrm{s}$ - offer unique opportunities to improve patient-provider communication and facilitate patient engagement. ${ }^{24-26}$

A growing body of evidence suggests that patient use of new technologies such as text messaging ${ }^{27-30}$ or email $^{31}$ to communicate with healthcare providers can lead to behavior change and improved health outcomes for select patient populations. Novel digital technology tools for engaging a wider group of patients are rapidly emerging. Patient portals, communication systems tethered to existing electronic health records (EHRs), are promoted by healthcare systems, but 
evidence concerning patient satisfaction with their use is mixed, and their impact on health outcomes is unclear. Patients report that the cumbersome functionality and standalone nature of these portals, partly as a result of their enhanced security features, are factors that limit their use. ${ }^{32}$ Additionally, patient race/ethnicity and literacy appear to be barriers to their uptake. ${ }^{33,34}$ Social media, including social networking sites (e.g. Facebook) and microblogs (e.g. Twitter), are widely used by adults across racial, ethnic, and socioeconomic groups, ${ }^{35-37}$ and they offer new channels for health communication. ${ }^{38}$ Research on social media, however, has focused more on interactions with other patients and obtaining and exchanging health information than on direct patient engagement. ${ }^{39}$ Patients' attitudes and experiences related to these social media are poorly understood, raising the question of whether health systems and practices should be investing in them. ${ }^{40,41}$

This study sought to examine and assess patient perceptions regarding communication technologies currently used by many adults, such as texting, email, and social media, as a means to engage with their clinician or other patients outside traditional office-based visits. One recent survey of retail pharmacy users found strong interest among patients in the use of email and Facebook to communicate with their providers. ${ }^{42}$ We surveyed a nationally representative sample of patients, examining their willingness to use these technologies in specific clinical examples. We focused on communicating different types of information, such as test results or health goals, as well as different types of interactions, for example with a doctor or with other patients, as patients may hold different views about engaging in these clinical activities. ${ }^{43}$

\section{METHODS}

\section{Participants and Survey Administration}

Participants were recruited from an online research panel assembled by GfK Knowledge Networks (GfK KnowledgePanel $\left.^{\mathbb{1}}\right)^{44}$ as part of a broader study on health information use and privacy. ${ }^{45,46}$ In order to create a nationally representative panel, GfK KnowledgePanel ${ }^{\circledR}$ members are recruited through probability-based sampling using random digit dialing and address-based sampling. This approach provides coverage of households with and without telephones, mobile phones, and home Internet access. Individuals without Internet access are provided with computer hardware and Internet capability in exchange for participation; those with Internet access are given modest cash compensation. This method of sampling and panel creation from probabilitybased samples yields estimates similar to those derived from random-digit-dialing telephone surveys. ${ }^{47}$

The study population was sampled from three racial/ethnic populations: non-Hispanic African American, non-Hispanic white, and Hispanic (African American and white bilingual English- and Spanish-speaking households). We oversampled
African American and Hispanic individuals to allow for sufficiently powered comparisons across the three racial/ethnic populations. Prior to survey administration, we decided to exclude participants who finished the survey in less than half the median completion time. Pretest piloting showed that these individuals had little item-to-item variation in their survey responses, suggesting a low level of attention to item content. ${ }^{46}$

The survey was administered electronically from 9 November through 2 December 2012. Spanish-speaking participants had the option of completing the survey in English or Spanish. The University of Pennsylvania Institutional Review Board approved the study protocol.

\section{Survey Instrument}

The survey was developed as part of a larger survey on health information use and privacy. We asked participants to rate their level of agreement with several different uses of communication technology. The first set of questions focused on participants' level of agreement with using four different communication channels (telephone, email, texting, social media) with two different information types (test results: "blood test results", health goals: "personal health goals such as an exercise plan") to communicate with their doctor: "I want my doctor to communicate with me about my personal health goals such as an exercise plan using..." We chose these two different information types, given that patients' attitudes toward communication about more discrete information may differ from those regarding more complex behavior-related information. We also assessed all participants' attitudes toward participating in a peer coaching program on social media: "Some people like meeting other people with similar medical conditions to share stories and coach each other. If my doctor offered me a way to join a group of patients on Facebook, I would join." Lastly, we assessed participants' attitudes toward receiving general health messages such as flu vaccine reminders from their doctor on Twitter: "If my doctor sent out health messages such as flu vaccine reminders on Twitter, I would sign up so I could get those messages." We measured participants' attitudes toward communication channels and technologies using five-point Likert scales ranging from "strongly disagree" to "strongly agree." We also collected information from participants on their health status, using validated survey questions, ${ }^{48}$ and on their use of other technology. To ensure content validity prior to survey administration, the survey was reviewed by content experts for feedback and pilot-tested on a separate sample of GfK KnowledgePanel participants.

\section{Demographics and Additional Information}

We obtained previously collected information about study participants from GfK Knowledge Networks, including race/ethnicity, income, educational attainment, sex, age, and residence in a rural or metropolitan area. We also obtained 
information about their use of other digital technologies, including the use of online banking and smartphones; however, these data were not available for all participants, due to the GfK Knowledge Networks approach of periodically collecting this information from panel members.

\section{Statistical Analysis}

Descriptive statistics were calculated to characterize respondents and their willingness to communicate via the different communication channels. The influence of individual characteristics on their willingness to communicate health goals with their doctor via text messaging (yes vs. no) were modeled using generalized estimating equations (GEE) with logit link and assuming an independent working correlation structure and robust variance estimates to account for the correlation of observations nested within respondents. Post-stratification weights were used to account for non-response.

We used chi-square tests to compare demographic characteristics between responders willing to communicate health goals and test results by email and text versus those willing to communicate via email but not text. Chi-square tests were also used to compared demographic characteristics between respondents interested in engaging other patients/doctors on Facebook and Twitter, and those who were not. We used SAS version 9.2 software for all statistical analyses. All tests were two-sided, and a $p$ value less than 0.05 was considered statistically significant.

\section{RESULTS}

Of the 5119 individuals invited to participate, $3336 \mathrm{com}$ pleted the survey (response rate, 65.2\%). After excluding 272 respondents who finished the survey in less than half the median time, the final analytic sample included 3064 participants, and their characteristics are presented in Table 1. Among respondents, more than half (58\%) reported using Facebook, and nearly two-thirds (64.1\%) used text messaging. Compared with respondents, persons who did not respond were more likely to be younger, less educated, and have lower income, and were slightly more likely to be female (data not shown, reported in previous work as part of larger study). ${ }^{46}$

In Table 2, we show respondents' willingness to communicate with their doctor through different channels. Overall, very few participants $(<4 \%)$ were willing to communicate with their physician about health goals or test results through a social media platform (Facebook or Twitter). More were willing to use text messaging, but the rates remained low $(<20 \%)$, even when limited to individuals who already used texting, Facebook, or online banking. About half of respondents were willing to use email, with higher rates among individuals with lower health status and who were current users of technology.
Table 1 Participant Characteristics (unweighted percentages)

\begin{tabular}{ll}
\hline \hline & $\begin{array}{l}\text { Overall (\%) } \\
(\boldsymbol{n}=\mathbf{3 0 6 4})\end{array}$ \\
\hline Age (years) & \\
18-29 & 13.2 \\
30-44 & 21.5 \\
45-59 & 32.4 \\
60+ & 32.9 \\
Female & 49.8 \\
Race/Ethnicity & 68.3 \\
White, Non-Hispanic & 14.9 \\
African American, Non-Hispanic & 16.8 \\
Hispanic & 85.7 \\
Lives in a metropolitan statistical area & 8.9 \\
Education & 29.1 \\
Less than high school & 30.4 \\
High school & 31.6 \\
Some college & 18.8 \\
Bachelor's degree or higher & 23.6 \\
Income & 19.0 \\
< 25,000 & 38.6 \\
\$25,000-49,999 & 82.4 \\
\$50,000-74,999 & \\
\$75,000 and above & 83.1 \\
Insured & 16.9 \\
Health Status & 45.1 \\
Excellent, Very Good, or Good & 58.0 \\
Fair or Poor & 10.3 \\
Has a smartphone $(n=2857)^{*}$ & 64.1 \\
Uses Facebook & 64.2 \\
Uses Twitter & \\
Uses Text Messaging & \\
Uses Online Banking $(n=2203)^{*}$ & \\
\hline
\end{tabular}

${ }^{*}$ Number of respondents who have a smartphone or use online banking

Among participants who used text messaging $(n=1965$, $64 \%$ of total), we analyzed participant characteristics independently associated with support for using text messaging to communicate with their doctor estimated from an adjusted and weighted GEE model (see Table 3). The information content was not an important factor; willingness to communicate about blood test results was not significantly different from willingness to communicate about personal health goals (OR: 1.08, $95 \%$ CI $0.952,1.22)$. The only factor significantly associated with support for the use of text messaging was race/ethnicity, with African American, non-Hispanic, and Hispanic participants more likely than white participants to be willing to use this method to communicate with their doctor. Age, education level, health status, and residence in a metropolitan area were not significantly associated with participant willingness to use text messaging for this communication.

Participants were most supportive of the use of email for communication. We were interested in a population that showed a proclivity for using this communication channel in order to determine qualities that might reflect willingness to use newer communication channels. Therefore, we examined factors associated with support for email and text messaging (or, conversely, lack of support). Among those who supported using email for communication about health goals $(n=379), 25.5 \%$ also supported using text messaging. Among those who 
Table 2 Percentage of Respondents Willing to Communicate with Doctor by Different Channels*

\begin{tabular}{|c|c|c|c|c|c|c|c|c|}
\hline $\begin{array}{l}\text { Type of Health } \\
\text { Information }\end{array}$ & Channel & $\begin{array}{l}\text { Overall } \\
\text { Population } \\
\%(n=3064)\end{array}$ & $\begin{array}{l}\text { Healthy } \\
\text { (Excellent, Very } \\
\text { Good, or Good) } \\
\%(n=508)\end{array}$ & $\begin{array}{l}\text { Unhealthy } \\
\text { (Fair or Poor) } \\
\%(n=2556)\end{array}$ & $p$ value $\dagger$ & $\begin{array}{l}\text { Facebook Users } \\
\%(n=1776)\end{array}$ & $\begin{array}{l}\text { Texting Users } \\
\%(n=1965)\end{array}$ & $\begin{array}{l}\text { Online Banking } \\
\text { System Users } \\
\%(n=1414)\end{array}$ \\
\hline Health Goals & Facebook & 3.1 & 4.7 & 2.8 & 0.03 & 3.5 & 3.3 & 1.8 \\
\hline Health Goals & Texting & 13.3 & 14.3 & 13.2 & 0.52 & 16.2 & 17.8 & 13.9 \\
\hline Health Goals & E-mail & 48.8 & 41.4 & 51.0 & $<0.0001$ & 56.1 & 57.6 & 61.0 \\
\hline Health Goals & Phone & 75.7 & 73.8 & 76.9 & 0.13 & 77.0 & 77.8 & 77.6 \\
\hline Test Results & Facebook & 1.0 & 1.0 & 1.0 & 0.89 & 1.2 & 1.0 & 0.5 \\
\hline Test Results & Texting & 13.1 & 13.1 & 13.5 & 0.81 & 16.0 & 18.3 & 14.9 \\
\hline Test Results & E-mail & 45.4 & 36.7 & 48.1 & $<0.0001$ & 51.3 & 52.7 & 57.0 \\
\hline Test Results & Phone & 86.1 & 84.5 & 87.8 & 0.045 & 88.7 & 88.8 & 90.3 \\
\hline
\end{tabular}

*Percentage of respondents who answered "agree" or "strongly agree"

"Chi-square analysis comparing "healthy" versus "unhealthy" respondents

supported the use of email for communication about test results ( $\mathrm{n}=367), 26.7 \%$ also supported using text messaging. In Table 4, we present factors associated with support for text messaging among respondents supportive of using email to communicate. Respondents who were willing to communicate using email and text messaging were more likely to be a racial/ethnic minority (African American, non-Hispanic, or Hispanic), less than 60 years of age, of lower socioeconomic status (lower education and income levels), with poorer health status, and were less likely to have insurance.

Only $11.7 \%(n=357)$ and $8.4 \%(n=257)$ of participants were interested in engaging in peer coaching with other patients through Facebook or receiving generalized health messages from their doctor via Twitter, respectively. Participants willing to join a group of similar patients on a

Table 3 Influence of Individual Characteristics on Participants' Willingness to Communicate Health Goals or Blood Tests with their Doctor via Text Messaging $(n=1965)$

\begin{tabular}{|c|c|c|c|}
\hline \multirow{2}{*}{$\begin{array}{l}\text { Individual Characteristics } \\
\text { Willingness to share health goals }\end{array}$} & \multirow{2}{*}{$\begin{array}{l}\text { Odds Ratio } \\
\text { Reference }\end{array}$} & \multicolumn{2}{|c|}{$\begin{array}{l}95 \% \\
\text { Confidence } \\
\text { Intervals }\end{array}$} \\
\hline & & - & - \\
\hline Willingness to share blood tests & 1.08 & 0.952 & 1.22 \\
\hline $18-29$ & Reference & _ & _ \\
\hline $30-44$ & 1.22 & 0.814 & 1.83 \\
\hline $45-59$ & 1.36 & 0.912 & 2.04 \\
\hline $60+$ & 1.08 & 0.693 & 1.69 \\
\hline Female & 0.782 & 0.600 & 1.02 \\
\hline \multicolumn{4}{|l|}{ Race/Ethnicity } \\
\hline African American, Non-Hispanic & 1.44 & 1.01 & 2.06 \\
\hline Hispanic & 1.80 & 1.25 & 2.59 \\
\hline White, Non-Hispanic & Reference & - & - \\
\hline Lives in a metropolitan area & 0.892 & 0.604 & 1.32 \\
\hline \multicolumn{4}{|l|}{ Education } \\
\hline Some college or above & 1.23 & 0.911 & 1.67 \\
\hline High school or less & Reference & - & - \\
\hline \multicolumn{4}{|l|}{ Health Status } \\
\hline Fair or Poor & 0.886 & 0.610 & 1.29 \\
\hline Excellent, Very good, or Good & Reference & - & - \\
\hline \multicolumn{4}{|l|}{ Income } \\
\hline$<\$ 25,000$ & Reference & - & - \\
\hline$\$ 25,000-49,999$ & 0.948 & 0.591 & 1.52 \\
\hline$\$ 50,000-74,999$ & 1.01 & 0.623 & 1.63 \\
\hline$\$ 75,000$ and above & 0.953 & 0.598 & 1.52 \\
\hline
\end{tabular}

social media site like Facebook were more likely to be younger, female, a racial/ethnic minority (African American, nonHispanic, or Hispanic), and living in a metropolitan area, and were less likely to have insurance, have a smartphone, and engage in social media use and text messaging than those not willing (see Table 5). Similar individual characteristics were found for participants willing to receive Twitter messages containing health messages such as influenza vaccine reminders from their doctor.

\section{DISCUSSION}

As various pressures move primary care toward a system of population health management, patients, providers, and clinical teams will need to make use of new technologies to communicate outside traditional office-based interactions. Our study has two key findings. First, despite regular use of new digital technology such as text messaging and social media, few participants supported using these tools for communicating with their physician's practice. Respondents were most willing to use email, but this willingness was shared by less than $50 \%$ of the overall study population. This stands in contrast to a study exploring patient willingness to use digital technology among a population of retail pharmacy users, which found both strong patient interest and self-reported current use of email and social media for communicating with their physicians. ${ }^{42}$ While many participants in our nationally representative sample used social media and text messaging, and already engaged in online activities such as banking, they seemed to differentiate between healthcare and non-healthcare use of these technologies. Determining the reasons for this seeming differentiation will be important for identifying strategies to promote technology adoption.

Our second key finding is that identifying users of technology is more important than focusing on certain demographic groups with regard to identifying patients that may be willing to adopt these technologies for healthcare. While individuals with poorer health status may be more willing to use email to 
Table 4 Support for Text Messaging Among Email Supporters

\begin{tabular}{|c|c|c|c|c|c|c|c|c|}
\hline \multirow{2}{*}{$\begin{array}{l}\text { Individual } \\
\text { Characteristics }\end{array}$} & \multicolumn{3}{|l|}{ Health Goals } & \multirow{2}{*}{$\begin{array}{l}p \\
\text { value* }\end{array}$} & \multicolumn{3}{|l|}{ Test Results } & \multirow{2}{*}{$\begin{array}{l}p \\
\text { value* }\end{array}$} \\
\hline & $\begin{array}{l}\text { Email Yes / } \\
\text { Text Yes } \\
n(\%)\end{array}$ & $\begin{array}{l}\text { Email Yes / } \\
\text { Text No } \\
n(\%)\end{array}$ & $\begin{array}{l}\text { Email No / } \\
\text { Text No } \\
n(\%)\end{array}$ & & $\begin{array}{l}\text { Email Yes / } \\
\text { Text Yes } \\
n(\%)\end{array}$ & $\begin{array}{l}\text { Email Yes / } \\
\text { Text No } \\
n(\%)\end{array}$ & $\begin{array}{l}\text { Email No / } \\
\text { Text No } \\
n(\%)\end{array}$ & \\
\hline \multicolumn{9}{|l|}{ Age (years) } \\
\hline $18-29$ & $58(15.5)$ & $169(15.4)$ & $165(11.2)$ & \multirow[t]{4}{*}{$<0.0001$} & $59(16.2)$ & $135(13.5)$ & $192(12.4)$ & \multirow[t]{4}{*}{$<0.0001$} \\
\hline $30-44$ & $96(25.7)$ & $236(21.5)$ & $301(20.4)$ & & $98(26.9)$ & $213(21.4)$ & $313(20.2)$ & \\
\hline $45-59$ & $134(35.8)$ & $370(33.6)$ & $453(30.6)$ & & $129(35.5)$ & $320(32.1)$ & $498(32.1)$ & \\
\hline $60+$ & $86(23.0)$ & $324(29.5)$ & $560(37.9)$ & & $78(21.4)$ & $329(23.0)$ & $549(35.3)$ & \\
\hline Female & $170(45.5)$ & $539(49.0)$ & $727(49.2)$ & 0.16 & $146(40.1)$ & $484(48.6)$ & $806(51.9)$ & 0.0002 \\
\hline \multicolumn{9}{|l|}{ Race/Ethnicity } \\
\hline White, Non-Hispanic & $201(53.7)$ & $806(73.3)$ & $1031(69.7)$ & \multirow[t]{3}{*}{$<0.0001$} & $232(63.7)$ & $743(74.5)$ & $1036(66.7)$ & \multirow[t]{3}{*}{0.0002} \\
\hline $\begin{array}{l}\text { African American, } \\
\text { Non-Hispanic }\end{array}$ & $76(20.3)$ & $128(11.7)$ & $225(15.2)$ & & $60(16.5)$ & $118(11.9)$ & $251(16.2)$ & \\
\hline Hispanic & $97(26.0)$ & $165(15.0)$ & $223(15.1)$ & & $72(19.8)$ & $136(13.6)$ & $265(17.1)$ & \\
\hline \multicolumn{9}{|c|}{ Lives in a metropolitan area } \\
\hline Yes & $332(88.8)$ & $989(90.0)$ & $1209(81.7)$ & \multirow[t]{2}{*}{$<0.0001$} & $320(87.9)$ & $902(90.5)$ & $1270(81.8)$ & \multirow[t]{2}{*}{$<0.0001$} \\
\hline No & $42(11.2)$ & $110(10.0)$ & $270(18.3)$ & & $44(12.1)$ & $95(9.5)$ & $282(18.2)$ & \\
\hline \multicolumn{9}{|l|}{ Education } \\
\hline Less than high school & $41(11.0)$ & $38(3.5)$ & $174(11.8)$ & \multirow[t]{4}{*}{$<0.0001$} & $32(8.8)$ & $42(4.2)$ & $175(11.3)$ & \multirow[t]{4}{*}{$<0.0001$} \\
\hline High school & $84(22.5)$ & $264(24.0)$ & $510(34.5)$ & & $84(23.1)$ & $229(23.0)$ & $535(34.5)$ & \\
\hline Some college & $124(33.2)$ & $331(30.1)$ & $441(29.8)$ & & $114(31.3)$ & $295(29.6)$ & $475(30.6)$ & \\
\hline $\begin{array}{l}\text { Bachelor's degree } \\
\text { or higher }\end{array}$ & $125(33.3)$ & $466(42.4)$ & $354(23.9)$ & & $134(36.8)$ & $431(43.2)$ & $367(23.6)$ & \\
\hline \multicolumn{9}{|l|}{ Income } \\
\hline$<\$ 25,000$ & $66(17.7)$ & $110(10.0)$ & $362(24.5)$ & \multirow[t]{4}{*}{$<0.0001$} & $63(17.3)$ & $96(9.6)$ & $377(24.3)$ & \multirow[t]{4}{*}{$<0.0001$} \\
\hline$\$ 25,000-49,999$ & $80(21.4)$ & $228(20.8)$ & $391(26.4)$ & & $70(19.2)$ & $196(19.7)$ & $410(26.4)$ & \\
\hline$\$ 50,000-74,999$ & $79(21.1)$ & $221(20.1)$ & $266(18.0)$ & & $73(20.1)$ & $205(20.6)$ & $282(18.2)$ & \\
\hline$\$ 75,000$ and above & $149(39.8)$ & $540(49.1)$ & $460(31.1)$ & & $158(43.4)$ & $500(50.1)$ & $483(31.1)$ & \\
\hline \multicolumn{9}{|l|}{ Insured } \\
\hline Yes & $289(77.3)$ & $965(87.8)$ & $1212(81.9)$ & \multirow[t]{2}{*}{$<0.0001$} & $281(77.2)$ & $878(88.1)$ & $1271(81.9)$ & \multirow[t]{2}{*}{$<0.0001$} \\
\hline No & $85(22.7)$ & $134(12.2)$ & $267(18.1)$ & & $83(22.8)$ & $119(11.9)$ & $281(18.1)$ & \\
\hline Health Status & & & & & & & & \\
\hline $\begin{array}{l}\text { Excellent, Very } \\
\text { Good, or Good }\end{array}$ & $1196(80.9)$ & $961(87.4)$ & $307(82.1)$ & 0.0002 & $1248(80.4)$ & $873(87.6)$ & $306(84.1)$ & $<0.0001$ \\
\hline Fair or Poor & $283(19.1)$ & $138(12.6)$ & $67(17.9)$ & & $304(19.6)$ & $124(12.4)$ & $58(15.9)$ & \\
\hline Has a smartphone & & & & & & & & \\
\hline Yes & $201(58.8)$ & $576(55.8)$ & $479(34.5)$ & $<0.0001$ & $215(64.0)$ & $509(54.4)$ & $515(35.5)$ & $<0.0001$ \\
\hline No & $141(41.2)$ & $457(44.2)$ & $908(65.5)$ & & $121(36.0)$ & $426(45.6)$ & $934(64.5)$ & \\
\hline Uses Facebook & & & & & & & & \\
\hline Yes & $261(69.8)$ & $721(65.6)$ & $747(50.5)$ & $<0.0001$ & $252(69.2)$ & $628(63.0)$ & 82253.0 & $<0.0001$ \\
\hline No & $113(30.2)$ & $378(34.4)$ & $732(49.5)$ & & $112(30.8)$ & $369(37.0)$ & $730(47.0)$ & \\
\hline Uses Twitter & & & & & & & & \\
\hline Yes & $69(18.4)$ & $157(14.3)$ & $117(7.9)$ & $<0.0001$ & $61(16.8)$ & (138 13.8) & $140(9.0)$ & $<0.0001$ \\
\hline No & $305(81.6)$ & $942(85.7)$ & $1362(92.1)$ & & $303(83.2)$ & $859(86.2)$ & $1412(91.0)$ & \\
\hline Uses Online Banking & & & & & & & & \\
\hline Yes & $185(73.7)$ & $662(23.7)$ & $533(52.4)$ & $<0.0001$ & $193(75.1)$ & $592(75.7)$ & $583(54.3)$ & $<0.0001$ \\
\hline No & $66(26.3)$ & $206(76.3)$ & $484(47.6)$ & & $64(24.9)$ & $190(24.3)$ & $490(45.7)$ & \\
\hline
\end{tabular}

${ }^{*}$ Chi-square analysis testing association of support for text messaging by individual characteristics

communicate with their provider, physicians should not use demographic factors like age, race/ethnicity, or socioeconomic status as a proxy for attitudes toward the use of technology. We found that younger and older patients who used text messaging were equally willing to adopt technology for communicating with their doctor, and that among current users of technology, attitudes were similar regardless of income or education. Reports suggest that a racial/ethnic "digital divide" continues to persist in the use of technology, with African American individuals trailing whites in overall Internet use and home broadband adoption, although these differences are not consistent across technology platforms or demographic groups. ${ }^{49,50}$ Hispanic and African American patients in our study were actually more willing to use digital technology - text messaging in particular-to communicate with their doctor. These communication technologies may hold promise for reaching out to these harder-to-reach underserved populations.

This study has several limitations. First, it is descriptive in nature. We asked participants about their attitudes regarding hypothetical uses of technology for communicating with their primary care team, and thus we do not know the extent to which these attitudes would translate to actual behavior if these communication channels were offered. Second, we did not ask respondents about available secure platforms for communication with providers, such as patient portals or secure webmail/email, as we were primarily interested in technology that patients were already using and engaged with more regularly. Third, attitudes toward digital technology are likely rapidly evolving with changes in adoption and use. Fourth, our respondents may not be fully representative of the US population of the three racial and ethnic groups we 
Table 5 Willingness to Use Social Media to Participate in Peer Coaching or Receive General Health Messages

\begin{tabular}{|c|c|c|c|c|c|c|}
\hline \multirow[t]{2}{*}{ Individual Characteristics } & \multicolumn{3}{|c|}{$\begin{array}{l}\text { Would Join a Facebook Page to Meet Other } \\
\text { Patients if Asked }\end{array}$} & \multicolumn{3}{|c|}{$\begin{array}{l}\text { Would ign Up to Receive Twitter Messages from } \\
\text { My Doctor }\end{array}$} \\
\hline & Agree $n(\%)$ & Disagree $n(\%)$ & $p$ value* & Agree $n(\%)$ & Disagree $n(\%)$ & $p$ value* \\
\hline \multicolumn{7}{|l|}{ Age (years) } \\
\hline $18-29$ & $67(16.8)$ & $333(83.2)$ & \multirow[t]{4}{*}{$<0.0001$} & 48 (11.9) & $354(88.1)$ & \multirow[t]{4}{*}{0.0002} \\
\hline $30-44$ & $100(15.3)$ & $552(84.7)$ & & $69(10.7)$ & $578(89.3)$ & \\
\hline $45-59$ & $125(12.6)$ & $862(87.4)$ & & $82(8.3)$ & $902(81.7)$ & \\
\hline $60+$ & $65(6.5)$ & $939(93.5)$ & & $58(5.8)$ & $939(94.2)$ & \\
\hline Female & $207(13.6)$ & $1310(86.4)$ & 0.001 & $127(8.4)$ & $1284(92.6)$ & 0.88 \\
\hline Race/Ethnicity & - & - & - & - & - & - \\
\hline White, Non-Hispanic & $215(10.3)$ & $1867(89.7)$ & 0.0004 & $129(6.2)$ & $1946(94.8)$ & $<0.0001$ \\
\hline African American, Non-Hispanic & $58(12.9)$ & $392(87.1)$ & & $44(9.9)$ & $402(90.1)$ & \\
\hline Hispanic & $84(16.4)$ & $427(83.6)$ & & $84(16.5)$ & $425(83.5)$ & \\
\hline \multicolumn{7}{|l|}{ Lives in a metropolitan area } \\
\hline Yes & $322(12.4)$ & $2285(87.6)$ & \multirow[t]{2}{*}{0.009} & $229(8.8)$ & $2366(91.2)$ & \multirow[t]{2}{*}{0.098} \\
\hline No & $35(8.0)$ & $401(92.0)$ & & $28(6.4)$ & $407(93.6)$ & \\
\hline Education & - & - & - & - & - & - \\
\hline Less than high school & $31(11.4)$ & $241(88.6)$ & \multirow{4}{*}{0.78} & $32(12.0)$ & $235(88.0)$ & \multirow[t]{4}{*}{0.034} \\
\hline High school & $96(10.9)$ & $788(89.1)$ & & $58(6.6)$ & $821(93.4)$ & \\
\hline Some college & $114(12.4)$ & $809(87.6)$ & & $80(8.7)$ & $840(91.3)$ & \\
\hline Bachelor's degree or higher & $116(12.0)$ & $848(88.0)$ & & $87(9.0)$ & $877(91.0)$ & \\
\hline Income & - & - & - & - & - & - \\
\hline$<\$ 25,000$ & $67(11.7)$ & $504(88.3)$ & \multirow[t]{4}{*}{0.73} & $56(9.9)$ & $508(90.1)$ & \multirow[t]{4}{*}{0.17} \\
\hline$\$ 25,000-49,999$ & $82(11.4)$ & $635(88.6)$ & & $55(7.7)$ & $658(92.3)$ & \\
\hline$\$ 50,000-74,999$ & $62(10.7)$ & $520(89.3)$ & & $39(6.7)$ & $541(93.3)$ & \\
\hline$\$ 75,000$ and above & $146(12.4)$ & $1027(87.5)$ & & $107(9.1)$ & $1066(90.9)$ & \\
\hline Insured & - & - & - & - & - & - \\
\hline Yes & $271(10.8)$ & $2245(89.2)$ & \multirow[t]{2}{*}{$<0.0001$} & $190(7.6)$ & $2315(92.3)$ & \multirow[t]{2}{*}{$<0.0001$} \\
\hline No & $86(15.6)$ & $441(84.4)$ & & $67(12.8)$ & $458(87.2)$ & \\
\hline \multicolumn{7}{|l|}{ Health Status } \\
\hline Excellent, Very Good, or Good & $298(11.8)$ & $2236(88.2)$ & \multirow[t]{2}{*}{0.85} & $213(8.4)$ & $2312(91.6)$ & \multirow[t]{2}{*}{0.98} \\
\hline Fair or Poor & $59(11.6)$ & $450(88.4)$ & & $44(8.7)$ & $461(91.3)$ & \\
\hline \multicolumn{7}{|l|}{ Has a smartphone } \\
\hline Yes & $171(13.3)$ & $1112(86.7)$ & \multirow[t]{2}{*}{0.002} & $143(11.2)$ & $1139(88.8)$ & \multirow[t]{2}{*}{$<0.001$} \\
\hline No & $149(9.5)$ & $1412(90.5)$ & & $96(6.2)$ & $1455(93.8)$ & \\
\hline \multicolumn{7}{|l|}{ Uses Facebook } \\
\hline Yes & $287(16.2)$ & $1481(83.8)$ & \multirow[t]{2}{*}{$<0.001$} & $189(10.7)$ & $1574(89.3)$ & $<0.001$ \\
\hline No & $70(5.6)$ & $1183(94.4)$ & & $68(5.4)$ & $1199(94.6)$ & \\
\hline Uses Twitter & & & & & & \\
\hline Yes & $67(21.4)$ & $246(78.6)$ & $<0.001$ & $77(24.8)$ & $234(75.2)$ & $<0.0001$ \\
\hline No & $290(10.6)$ & $2440(89.4)$ & & $180(6.6)$ & $2539(3.4)$ & \\
\hline Uses Text Messaging & & & & & & \\
\hline Yes & $284(14.5)$ & $1672(85.5)$ & $<0.001$ & $209(10.7)$ & $1741(89.3)$ & $<0.0001$ \\
\hline No & $73(6.7)$ & $1014(93.3)$ & & $48(4.4)$ & $1032(95.6)$ & \\
\hline Uses Online Banking & & & & & & \\
\hline Yes & $173(12.3)$ & $1235(87.7)$ & 0.06 & $123(8.7)$ & $1286(91.3)$ & 0.068 \\
\hline No & $76(9.6)$ & $712(90.4)$ & & $51(6.5)$ & $730(93.5)$ & \\
\hline
\end{tabular}

${ }^{*}$ Chi-square analysis testing association of support for Facebook and Twitter use and individual characteristics

sampled, and there may be important differences between those broad racial or ethnic categories that our study could not uncover. Finally, our findings could be susceptible to non-response bias, as there may be differences in attitudes between those who are willing to participate in a survey research panel and those who are not. However, we achieved a relatively high response rate and used poststratification weights to adjust for non-response.

As healthcare extends beyond the traditional in-person interactions between physician and patient, and as more health-related information is captured on a variety of digital devices and media, clinical practices and patients will need to work together to achieve the potential of new communication technologies in improving patient engagement. Privacy concerns and patient preference for interacting with physicians in person, which have been identified as patient concerns limiting the uptake of
EHR-connected communication systems, ${ }^{43}$ may be reasons for patient reluctance to use new communication technologies. These are important questions for future research. In the meantime, practices could begin to experiment with these technologies, focusing on individual groups that are current technology users and are primed for change. Text messaging services, for example, have shown success in adding chronic care and disease prevention management, with services ranging from medication reminders for asthma patients, or succinct help or warning messages for diabetic patients with blood glucose levels outside their individual range parameters, to simple patient reminders about preventive visits or services. ${ }^{27-29}$ Beyond the technologies that we asked about in our study is the emergence of other personal health technologies such as wearable devices and mobile smartphone apps, which could further connect physicians and 
patients in novel ways. ${ }^{51}$ Helping patients overcome barriers to the use of new communication technology for healthcare is the future of population health management and patient engagement outside the traditional clinic setting.

\section{Acknowledgments: None.}

Conflict of Interest Statement: All authors have no potential conflicts of interest to report.

Support: This research was supported by grant 5R21HG006047-02 from the National Human Genome Research Institute.

Corresponding Author: Brian P Jenssen, MD; Robert Wood Johnson Foundation Clinical Scholars Program, University of Pennsylvania, 1310 Blockley Hall, 423 Guardian Drive, Philadelphia, PA 19104 USA (e-mail: jenssenb@email.chop.edu).

\section{REFERENCES}

1. Agency for Healthcare Research and Guality. Patient Centered Medical Home Resource Center [Internet]. Available from: http://pcmh. ahrq.gov/

2. Jackson GL, Powers BJ, Chatterjee R, Bettger JP, Kemper AR, Hasselblad V, et al. Improving patient care. The patient centered medical home. A Systematic Review. Ann Intern Med. 2013;158(3):169-78.

3. Berkowitz SA, Pahira JJ. Accountable Care Organization Readiness and Academic Medical Centers. Acad Med. 2014;89(9):1210-5.

4. Berwick DM. Launching Accountable Care Organizations - The Proposed Rule for the Medicare Shared Savings Program. N Engl J Med. 2011;364(16):e32.

5. DeVore S, Champion RW. Driving Population Health Through Accountable Care Organizations. Health Aff (Millwood). 2011;30(1):41-50.

6. Robert A. Berenson MD. Shared Savings Program for Accountable Care Organizations: A Bridge to Nowhere? Am J Manag Care [Internet]. 2010 [cited 2015 Jan 17]; 16(October 2010 10). Available from: http://www. ajmc.com/publications/issue/2010/2010-10-vol16-n10/AJMC_10oct Berenson 721to726/

7. Hussey PS, Ridgely MS, Rosenthal MB. The PROMETHEUS Bundled Payment Experiment: Slow Start Shows Problems In Implementing New Payment Models. Health Aff (Millwood). 2011;30(11):2116-24.

8. Conrad DA, Grembowski D, Hernandez SE, Lau B, Marcus-Smith M Emerging Lessons From Regional and State Innovation in Value-Based Payment Reform: Balancing Collaboration and Disruptive Innovation. Milbank Q. 2014;92(3):568-623.

9. Cusack CM, Knudson AD, Kronstadt JL, Singer RF, Brown AL. PracticeBased Population Health: Information Technology to Support Transformation to Proactive Primary Care (Prepared for the AHRQ National Resource Center for Health Information Technology under Contract No. 290-04-0016.) AHRQ Publication No. 10-0092-EF [Internet]. Rockville, MD: Agency for Healthcare Research and Quality; 2010 Available from: http://pcmh.ahrq.gov/sites/default/files/attachments/ Information $\% 20$ Technology $\% 20$ to\%20Support $\% 20$ Transformation $\% 20 t$ o\%20Proactive $\% 20$ Primary\%20Care.pdf

10. Bodenheimer T, Ghorob A, Willard-Grace $\mathbf{R}$, Grumbach $\mathbf{K}$. The 10 Building Blocks of High-Performing Primary Care. Ann Fam Med. 2014; 12(2):166-71.

11. Kindig DA. Understanding Population Health Terminology. Milbank Q. 2007;85(1):139-61.

12. Kilo CM, Wasson JH. Practice Redesign And The Patient-Centered Medical Home: History, Promises, And Challenges. Health Aff (Millwood). 2010;29(5):773-8.

13. Kanter M, Martinez O, Lindsay G, Andrews K, Denver C. Proactive office encounter: a systematic approach to preventive and chronic care at every patient encounter. Perm J. 2010; 14(3):38-43.

14. Center for Advancing Health. A new definition of patient engagement: what is engagement and why is it important? [Internet]. Washington (DC): CFAH; 2010. Available from: http://www.cfah.org/pdfs/CFAH Engagement_Behavior_Framework_current.pdf
15. Neuwirth EEB, Schmittdiel JA, Tallman K, Bellows J. Understanding panel management: a comparative study of an emerging approach to population care. Perm J. 2007;11(3):12-20.

16. Loo TS, Davis RB, Lipsitz LA, et al. ELectronic medical record reminders and panel management to improve primary care of elderly patients. Arch Intern Med. 2011;171(17):1552-8.

17. Chen EH, Bodenheimer T. Improving population health through teambased panel management: Comment on "electronic medical record reminders and panel management to improve primary care of elderly patients.". Arch Intern Med. 2011;171(17):1558-9.

18. Boivin A, Lehoux P, Lacombe R, Burgers J, Grol R. Involving patients in setting priorities for healthcare improvement: a cluster randomized trial. Implement Sci. 2014;9(1):24.

19. Hoffman RM, Steel SR, Yee EFT, Massie L, Schrader RM, Moffett ML, et al. A system-based intervention to improve colorectal cancer screening uptake. Am J Manag Care. 2011;17(1):49-55.

20. Jacobson Vann JC, Szilagyi P. Patient reminder and patient recall systems to improve immunization rates. Cochrane Database Syst Rev. 2005;(3):CD003941.

21. Stockwell MS, Kharbanda EO, Martinez RA, Vargas CY, Vawdrey DK, Camargo S. Effect of a text messaging intervention on influenza vaccination in an urban, low-income pediatric and adolescent population: a randomized controlled trial. JAMA. 2012;307(16):1702-8.

22. Wennberg DE, Marr A, Lang L, O'Malley S, Bennett G. A randomized trial of a telephone care-management strategy. N Engl J Med. 2010;363(13): 1245-55.

23. Coleman K, Austin BT, Brach C, Wagner EH. Evidence On The Chronic Care Model In The New Millennium. Health Aff (Millwood). 2009;28(1):7585.

24. Scholle SH, Torda P, Peikes D, Han E, Genevro J. Engaging Patients and Families in the Medical Home. (Prepared by Mathematica Policy Research under Contract No. HHSA290200900019I TO2.) [Internet]. AHRQ Publication No. 10-0083-EF. Rockville, MD: Agency for Healthcare Research and Quality; 2010. Available from: http://pcmh.ahrq.gov/page/ engaging-patients-and-families-medical-home

25. Moreno L, Peikes D, Krilla A. Necessary But Not Sufficient: The HITECH Act and Health Information Technology's Potential to Build Medical Homes. (Prepared by Mathematica Policy Research under contract no. HHSA290200900019ITO2.) [Internet]. AHRQ Publication no. 10-0080-EF. Rockville, MD: Agency for Healthcare Research and Quality; 2010. Available from: http://pcmh.ahrq.gov/sites/default/files/attachments/ Necessary\%20But\%20Not\%20Sufficient_The\%20HITECH\%20Act.pdf

26. Ricciardi L, Mostashari F, Murphy J, Daniel JG, Siminerio EP. A National Action Plan To Support Consumer Engagement Via E-Health. Health Aff (Millwood). 2013;32(2):376-84.

27. Vodopivec-Jamsek V, de Jongh T, Gurol-Urganci I, Atun R, Car J. Mobile phone messaging for preventive health care. Cochrane Database Syst Rev. 2012;12:CD007457.

28. De Jongh T, Gurol-Urganci I, Vodopivec-Jamsek V, Car J, Atun R. Mobile phone messaging for facilitating self-management of long-term illnesses. Cochrane Database Syst Rev. 2012;12:CD007459.

29. Car J, Gurol-Urganci I, de Jongh T, Vodopivec-Jamsek V, Atun R. Mobile phone messaging reminders for attendance at healthcare appointments. Cochrane Database Syst Rev. 2012;7:CD007458.

30. Buis LR, Hirzel L, Turske SA, Des Jardins TR, Yarandi H, Bondurant P. Use of a text message program to raise type 2 diabetes risk awareness and promote health behavior change (part II): assessment of participants' perceptions on efficacy. J Med Internet Res. 2013;15(12):e282.

31. De Jong CC, Ros WJ, Schrijvers G. The effects on health behavior and health outcomes of Internet-based asynchronous communication between health providers and patients with a chronic condition: a systematic review. J Med Internet Res. 2014;16(1):e19.

32. Hsiao AL, Bazzy-Asaad A, Tolomeo C, Edmonds D, Belton B, Benin AL. Secure Web Messaging in a Pediatric Chronic Care Clinic: A Slow Takeoff of "Kids' Airmail.". Pediatrics. 2011;127(2):e406-13.

33. Goldzweig CL, Orshansky G, Paige NM, Towfigh AA, Haggstrom DA Miake-Lye I, et al. Electronic patient portals: evidence on health outcomes, satisfaction, efficiency, and attitudes: a systematic review. Ann Intern Med. 2013;159(10):677-87.

34. Irizarry T, DeVito Dabbs A, Curran CR. Patient Portals and Patient Engagement: A State of the Science Review. J Med Internet Res. 2015; 17(6):e148.

35. Fox S. Health and Technology in the U.S. [Internet]. Pew Research Center: Internet, Science \& Tech. 2013 [cited 2015 Jul 29]. Available from: http:// www.pewinternet.org/2013/12/04/health-and-technology-in-the-u-s / 
36. Pew Research Center. Internet User Demographics [Internet]. Pew Research Center: Internet, Science \& Tech. 2014 [cited 2015 Jul 31]. Available from: http://www.pewinternet.org/data-trend/internet-use/latest-stats/

37. Pew Research Center. Social Networking Fact Sheet [Internet]. Pew Research Center: Internet, Science \& Tech. 2014 [cited 2015 Aug 4]. Available from: http://www.pewinternet.org/fact-sheets/social-networking-fact-sheet/

38. Grajales FJ, Sheps S, Ho K, Novak-Lauscher H, Eysenbach G. Social media: a review and tutorial of applications in medicine and health care. $\mathrm{J}$ Med Internet Res. 2014;16(2):e13.

39. Moorhead SA, Hazlett DE, Harrison L, Carroll JK, Irwin A, Hoving C. A new dimension of health care: systematic review of the uses, benefits, and limitations of social media for health communication. J Med Internet Res. 2013;15(4):e85

40. Or CKL, Karsh B-T. A Systematic Review of Patient Acceptance of Consumer Health Information Technology. J Am Med Inform Assoc. 2009; 16(4):550-60

41. Househ M, Borycki E, Kushniruk A. Empowering patients through social media: the benefits and challenges. Health Informatics J. 2014;20(1):50-8.

42. Lee JL, Choudhry NK, Wu AW, Matlin OS, Brennan TA, Shrank WH. Patient Use of Email, Facebook, and Physician Websites to Communicate with Physicians: A National Online Survey of Retail Pharmacy Users. J Gen Intern Med. 2015

43. The National Partnership for Women \& Families. Engaging Patients and Families: How Consumers Value and Use Health IT [Internet]. 2014. Available from: http://www.nationalpartnership.org/research-library/ health-care/HIT/engaging-patients-and-families.pdf
44. GfK Knowledge Networks. KnowledgePanel design summary [Internet]. 2013 [cited 2015 Jan 4]. Available from: http://www.knowledgenetworks. com/knpanel/docs/knowledgePanel(R)-design-summary-description.pdf

45. Grande D, Mitra N, Shah A, Wan F, Asch DA. The importance of purpose: moving beyond consent in the societal use of personal health information. Ann Intern Med. 2014;161(12):855-62.

46. Grande D, Mitra N, Shah A, Wan F, Asch DA. Public preferences about secondary uses of electronic health information. JAMA Intern Med. 2013;173(19): 1798-806.

47. Yeager DS, Krosnick JA, Chang L, Javitz HS, Levendusky MS, Simpser A, et al. Comparing the Accuracy of RDD Telephone Surveys and Internet Surveys Conducted with Probability and Non-Probability Samples. Public Opin Q. 2011;75(4):709-47.

48. 2010 behavioral risk factor surveillance system questionnaire [Internet]. Atlanta, GA: Centers for Disease Control and Prevention; 2009. Available from: http://www.cdc.gov/brfss/questionnaires/pdfques/2010brfss.pdf

49. Zickuhr K. Digital Differences [Internet]. Pew Research Center's Internet \& American Life Project. 2012 [cited 2015 Mar 8]. Available from: http:// www.pewinternet.org/2012/10/17/digital-differences-2/

50. Smith A. African Americans and Technology Use [Internet]. Pew Research Center's Internet \& American Life Project. 2014 [cited 2015 Mar 8]. Available from: http://www.pewinternet.org/2014/01/06/african-americans-and-technology-use/

51. Partners HealthCare to Boost and Sustain Personal Health Tracker Use [Internet]. RWJF. [cited 2015 Apr 12]. Available from: http://www.rwjf.org/ en/library/articles-and-news/2015/03/partners-healthcare-receivesgrant-to-create-engagement-engine.html 